\title{
Effectiveness and safety of aerobic exercise for rheumatoid arthritis: a systematic review and meta-analysis of randomized controlled trials
}

\author{
Hui Ye, Heng Weng, Yue Xu, Lulu Wang, Qing Wang* ${ }^{*}$ and Guihua X ${ }^{*}$
}

\begin{abstract}
Background: Rheumatoid arthritis (RA) can cause severe physical impairment and a reduced quality of life, and there is limited evidence for any effective intervention. Aerobic exercise may be beneficial for improving symptoms. Therefore, the purpose of this meta-analysis was to evaluate the effectiveness and safety of aerobic exercise for rheumatoid arthritis patients.

Methods: PubMed, The Cochrane Library, Web of Science, EMBASE, CNKI, WanFang Data and VIP databases were searched. Randomized controlled trials of the effectiveness and safety of aerobic exercise for rheumatoid arthritis were included. Risks of bias were assessed by two independent reviewers using the methods described in the RevMan 5.3, GRADEpro and the Cochrane Handbook. Meta-analyses were performed to investigate the effects of aerobic exercise on rheumatoid arthritis.
\end{abstract}

Results: A total of 13 RCTs were included, including 967 rheumatoid arthritis patients. The Meta-analysis results showed that aerobic exercise can improve functional ability $[\mathrm{MD}=-0.25,95 \% \mathrm{Cl}(-0.38,-0.11), P=0.0002]$, relieve pain $[S M D=-0.46,95 \% \mathrm{Cl}(-0.90,-0.01), P=0.04]$, increase aerobic capacity $[\mathrm{MD}=2.41,95 \% \mathrm{Cl}(1.36,3.45)$, $P<0.00001]$ and improve the Sit to Stand test score $[\mathrm{MD}=1.60,95 \% \mathrm{Cl}(0.07,3.13), P=0.04]$ with statistically significant differences.

Conclusion: Generally, aerobic exercise is beneficial and safe for RA patients and has a certain alleviating effect on the disease, such as functional ability improvement, pain relief and aerobic capacity increase. Limited by the quantity and quality of the included studies, future research with higher-quality studies needs to be conducted to verify the above conclusions.

Trial registration: PROPERO registration number: CRD42021242953.

Keywords: Aerobic exercise, Rheumatoid arthritis, Function ability, Disease activity, Systematic review, Meta-analysis, Randomized controlled trials

*Correspondence: wangqing@njucm.edu.cn; guihua.xu@njucm.edu.cn School of Nursing, Nanjing University of Chinese Medicine, No. 138, Xianlin St., Box 064, Nanjing 210023, People's Republic of China

\section{Introduction}

Rheumatoid arthritis (RA) is a chronic and systemic inflammatory autoimmune disease that mainly involves the joints [1], with an estimated prevalence between 0.3 and $1 \%$. It is more commonly diagnosed in women [2, 3]. The age-standardized prevalence and incidences of 
RA are increasing globally [4]. RA patients usually show painful symmetrical joint swelling, morning stiffness and limited functioning of the joints [5], leading to functional disability to varying degrees [6] and a decline in quality of life. The pathological process of RA involves abnormal activation and proliferation of macrophages and $B$ and $\mathrm{T}$ lymphocytes, along with oxidative stress damage in human body, causing joint destruction, activating the immune system, and ultimately leading to a chronic inflammatory response $[7,8]$.

Currently, in RA treatment, priority is given to pharmacotherapy. Nonsteroidal anti-inflammatory drugs (NSAIDs) and disease-modifying antirheumatic drugs (DMARDs) are commonly used in clinical practice [9, 10]. The advent of biological therapeutics as an important segment of pharmacological treatment has been a major advance in the treatment of RA [11]. Medicine has achieved certain effects; however, there are disadvantages of adverse drug reactions, such as gastrointestinal adverse reactions, high cost and limited efficacy [12, 13], and nonpharmacological therapies are providing emerging support. Therefore, people have become increasingly aware of the importance of exploring other treatments for RA.

An increasing number of studies have suggested that increasing physical activity and exercise can improve symptoms and reduce the impact of systemic manifestations in RA [14, 15]. Physical activity is defined as any bodily movement produced by skeletal muscles that results in energy expenditure. Exercise is a subset of physical activity that is planned, structured, repetitive and has as a final or an intermediate objective the improvement or maintenance of physical fitness [16]. Exercise modalities, including aerobic exercise, resistance training and strength training, have been proven to be beneficial to the disease management of RA [17]. Therapeutic exercise can increase biomolecular suppression of arthritis through the suppression of inflammatory cytokine expression, consequently suppressing joint destruction [18]. Physical activity has been recommended to be a component of standard care for RA patients by The European League Against Rheumatism [19].

Aerobic exercise predominantly depends on the aerobic energy-generating process, including jogging, walking and cycling, and aims to increase peak oxygen consumption $\left(\mathrm{VO}_{2} \mathrm{max}\right)$ by increasing the heart rate to $50 \%-80 \%$ of the maximum heart rate [20]. An investigation found a significant correlation between aerobic exercise habits and the onset of RA, and good aerobic exercise habits can reduce the risk of RA [21]. Researchers have found that aerobic exercise can significantly reduce joint damage [22], reduce the risk of cardiovascular disease [23], relieve symptoms of fatigue [24], improve the muscle strength of RA patients [25] and improve their quality of life [26]. At the same time, aerobic exercise has the advantages of having few toxic side effects, has a low cost, and is generally acceptable to patients.

To summarize the latest evidence of an effect of an aerobic exercise program in rheumatoid arthritis and to obtain a better estimate of the mean effect, we performed the current meta-analysis. This study followed AMSTAR 2.0 [27] guidance for systematic meta-analyses, reported the data in accordance with the Preferred Reporting Items for Systematic Reviews and Meta-Analyses guidelines [28], provided evidence of the methodological and reporting quality supporting the intervention impact, and clarified the effects and safety of aerobic exercise for RA patients.

\section{Methods}

\section{Protocol and registration}

This systematic review has been registered in PROSPERO, 2021 (registration number: CRD42021242953). It was completed and structured according to the Preferred Reporting Items for Systematic Reviews and Meta-Analyses (PRISMA) guidelines.

\section{Search strategy}

This systematic review and meta-analysis were performed in accordance with the PRISMA statement. The search was conducted by two reviewers, independent of each other. Randomized controlled trials (RCTs) and matched case studies were identified by searching PubMed, The Cochrane Library, Web of Science, EMBASE, and three Chinese electronic databases (China National Knowledge Infrastructure, Chinese VIP Information Database and WanFang Med Database) from 2000 until January 2022, using medical subject heading (MeSH) terms and all synonyms for "rheumatoid arthritis" in combination with the MeSH term and all synonyms for "aerobic exercise". In addition, we manually searched the references of the included literature to supplement access to all relevant literature. The search terms and strategy for PubMed are provided in Appendix 1. References to all identified publications were entered into reference managing software (Endnote version X9.3.3).

\section{Selection criteria}

Studies that met the following eligibility criteria were included: (1) designed as an RCT or matched case study; (2) published in English or Chinese; (3) patients, irrespective of sex or age, who were already clinically diagnosed with rheumatoid arthritis as defined by the American College of Rheumatology criteria or European League Against Rheumatism 2010 classification criteria [29]; (4) aerobic exercise interventions performed at $50-90 \%$ of 
the maximal heart rate, including walking, cycling, jogging, etc.; (5) presence of a control group, including but not limited to usual care, health education, or other exercise methods. All other treatments were required to be consistent between the experimental group and the control group. (6) Predefined inclusion criteria were data on functional ability, disease activity, joint counts, inflammatory markers, pain and aerobic capacity. As part of a sensitive search strategy, no restriction was initially made for specific outcomes. The exclusion criteria mainly were studies that were repeated publications, the full text was not available, the original research data were missing or the necessary data could not be extracted.

\section{Data extraction, endpoints}

Two researchers screened the literature independently, extracted the data and cross-checked them. Disagreements were resolved through discussion or negotiation with a third reviewer. Titles and abstracts were read first to exclude any obviously irrelevant literature. Next, the full texts of the remaining articles were reviewed for final inclusion. The data extraction content included (1) basic information of the included research: title, author, year, etc.; (2) baseline characteristics and intervention measures; (3) outcome indicators [30]: functional ability assessed by the Health Assessment Questionnaire-Disability index (HAQ-DI); disease activity assessed by the Disease Activity Score in 28 joints (DAS28); joint count including tender joint count (TJC), swollen joint count (SJC) and Ritchie Articular Index (RAI), inflammatory markers including CRP and ESR; pain measured with the visual analogue scale (VAS) or the Short Form of the McGill Pain Questionnaire; and aerobic capacity assessed by $\mathrm{VO}_{2}$ max and the Sit to Stand (STS) test.

\section{Data analysis and synthesis}

Tables and forest plots were produced to tabulate and visually display the results of the individual studies and syntheses. RevMan5.3 software was used for statistical analysis. Since the measure of dispersion for change was not always available, we imputed a change-from-baseline standard deviation (SD) using a correlation coefficient as recommended by the Cochrane Handbook [31]. The measurement data used the mean difference (MD) or standard mean difference (SMD) as the effect analysis statistics, and each effect size provided a 95\% CI. The heterogeneity among the results of the included studies was analysed by $x^{2}$ tests (test level at $\alpha=0.1$ ), and the degree of heterogeneity was quantitatively judged by combining with $\mathrm{I}^{2}$. Given $\mathrm{I}^{2}<50 \%$ and $p>0.1$, a fixed-effects model was used for analysis; if $\mathrm{I}^{2}>50 \%$ and $p<0.1$, a randomeffects model was applied. The level of meta-analysis was set to $\alpha=0.05$. In addition, subgroup analysis was adopted. Two subgroups, short-term $(\leq 16 \mathrm{w})$ and longterm $(>16 \mathrm{w})$, were divided according to the length of the intervention.

\section{Study quality assessments}

The included studies' risk of bias was evaluated independently and cross-checked by two investigators. The quality of the selected studies was scored using the quality critical appraisal criteria for RCTs, which is recommended by the Cochrane Handbook for Systematic Reviews of Interventions [31]. According to the Handbook, each item is rated as "low risk of bias", "unclear risk of bias", or "high risk of bias".

\section{Sensitivity analysis}

Sensitivity analysis was conducted to evaluate the robustness of the meta-analysis by assessing the influence of an individual study on the overall MD. We examined the effect of removing each study individually from the meta-analysis.

\section{Evidence quality assessment}

The overall quality of the evidence for each outcome was rated by two reviewers using the Grading of Recommendations Assessment, Development, and Evaluation (GRADE) criteria [32]. In this system, the quality of the evidence is rated at one of four levels: high quality, moderate quality, low quality, and very low quality.

\section{Results \\ Study selection}

A total of 3798 articles were retrieved from 7 databases and other sources, among which 2962 remained after duplicates were removed. By browsing the title and abstract, 2930 articles were screened out for inappropriate intervention measures, study types, etc. The remaining 32 were assessed in full text independently against the eligibility criteria by two researchers. Nineteen articles were excluded: 8 articles' intervention was not aerobic exercise; 7 articles' outcome indicators did not meet the inclusion criteria; 2 articles' study type did not match; and 2 articles had incomplete data results. Thirteen RCTs were finally included [33-45], studying a total of 967 RA patients. The study flow diagram for the systematic search process is shown in Fig. 1.

\section{Characteristics of the included studies}

Table 1 summarizes the characteristics of the included studies. Thirteen trials were published between 2000 and 2020, and all of them were published in English. All patients were diagnosed with RA, accompanied by different degrees of functional status, and the average age ranged from 45 to 70.11 . Aerobic exercise interventions 


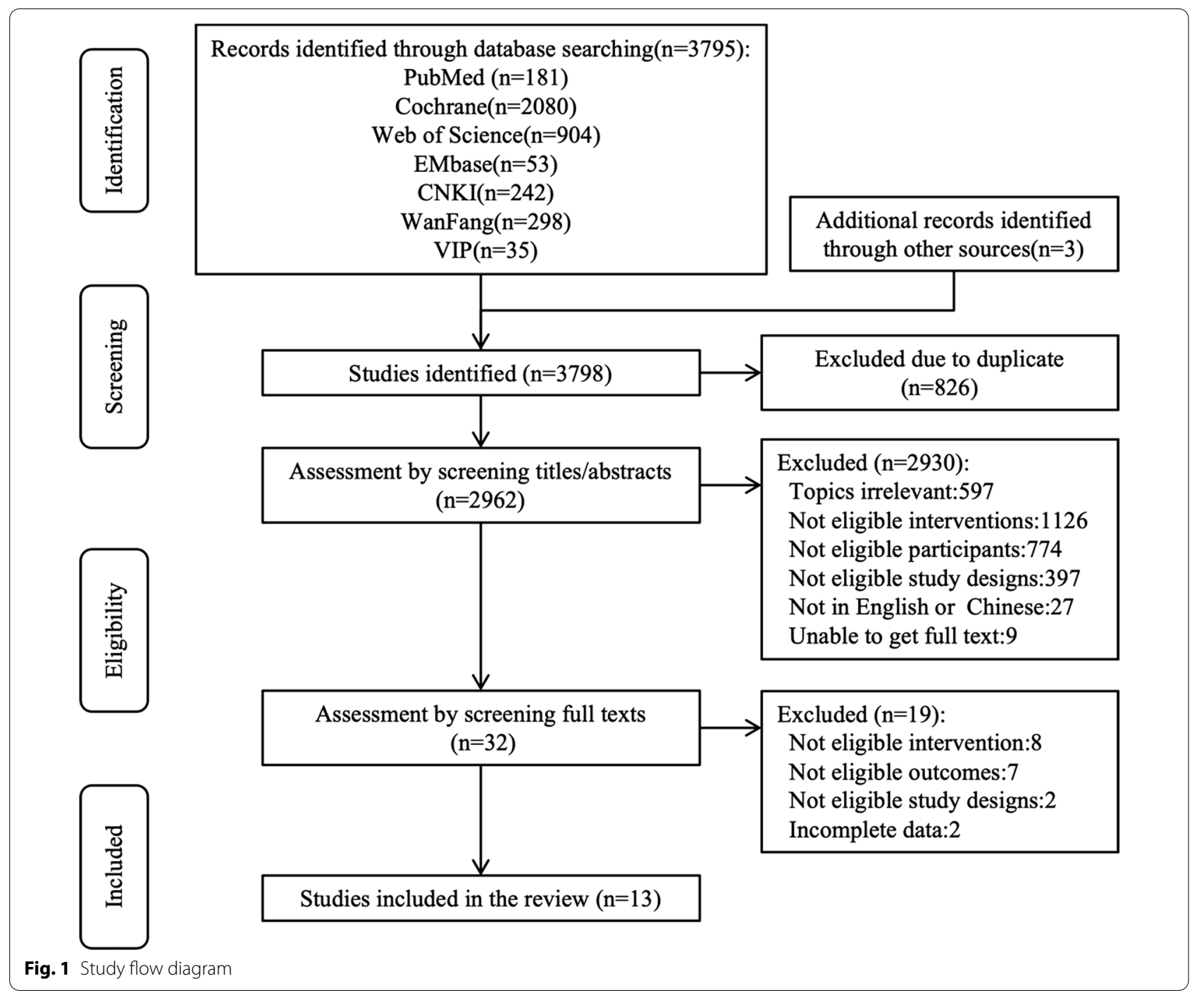

included bicycle riding, running on a treadmill, jogging, and walking. The control group underwent a range of usual care in 7 studies [33, 34, 36, 38, 39, 41, 44], motion exercises in 1 study [35], education programs in 3 studies $[37,40,45]$ and home-based nonaerobic exercises in 2 studies $[42,43]$. (Table 1 ).

\section{Quality appraisal}

The risk of bias is shown in Fig. 2. Three trials [35, 38, 41] $(23.08 \%)$ had inadequate random sequence generation due to only stating that they were randomized without describing a specific random method. One trial [40] (7.69\%) lacked a randomized design. Five trials [33, 37, $39,42,43](38.46 \%)$ had allocation concealment by using sealed and opaque envelopes or sealed tickets, and the other trials did not report the use of allocation concealment. None of the trials reported the blinding of participants and personnel. However, in trials of aerobic exercise interventions, it was difficult to blind the healthcare provider or participant; moreover, the primary outcomes mainly were objective indicators that were hardly affected by blinding, so we regarded this aspect as low risk. Two trials $[38,44](15.38 \%)$ were rated as high risk for not reporting assessor blinding. Two trials [37, 40] (15.38\%) were rated as unclear risk for not reporting a partial outcome indicator. Two other trials [34, 38] $(15.38 \%)$ were rated as at other high-risk bias based on the unbalanced sample size between two groups and slight differences between the groups at baseline, respectively (Fig. 2).

\section{Assessment of efficacy}

For the included studies, we performed a meta-analysis of 7 outcomes: functional ability, disease activity, joint counts, inflammatory markers, pain, aerobic capacity and 


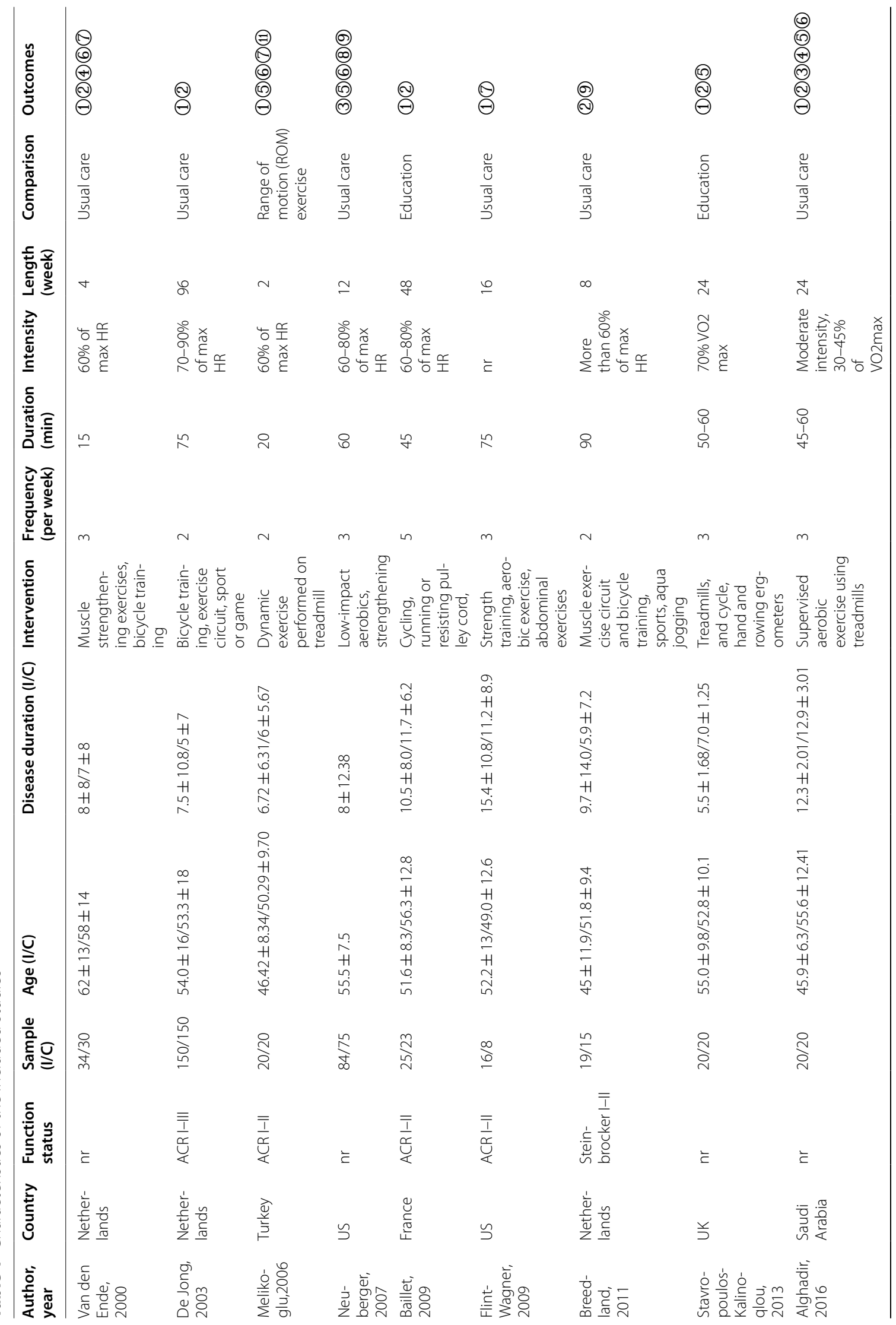


Ye et al. BMC Sports Science, Medicine and Rehabilitation

(2022) $14: 17$

Page 6 of 15

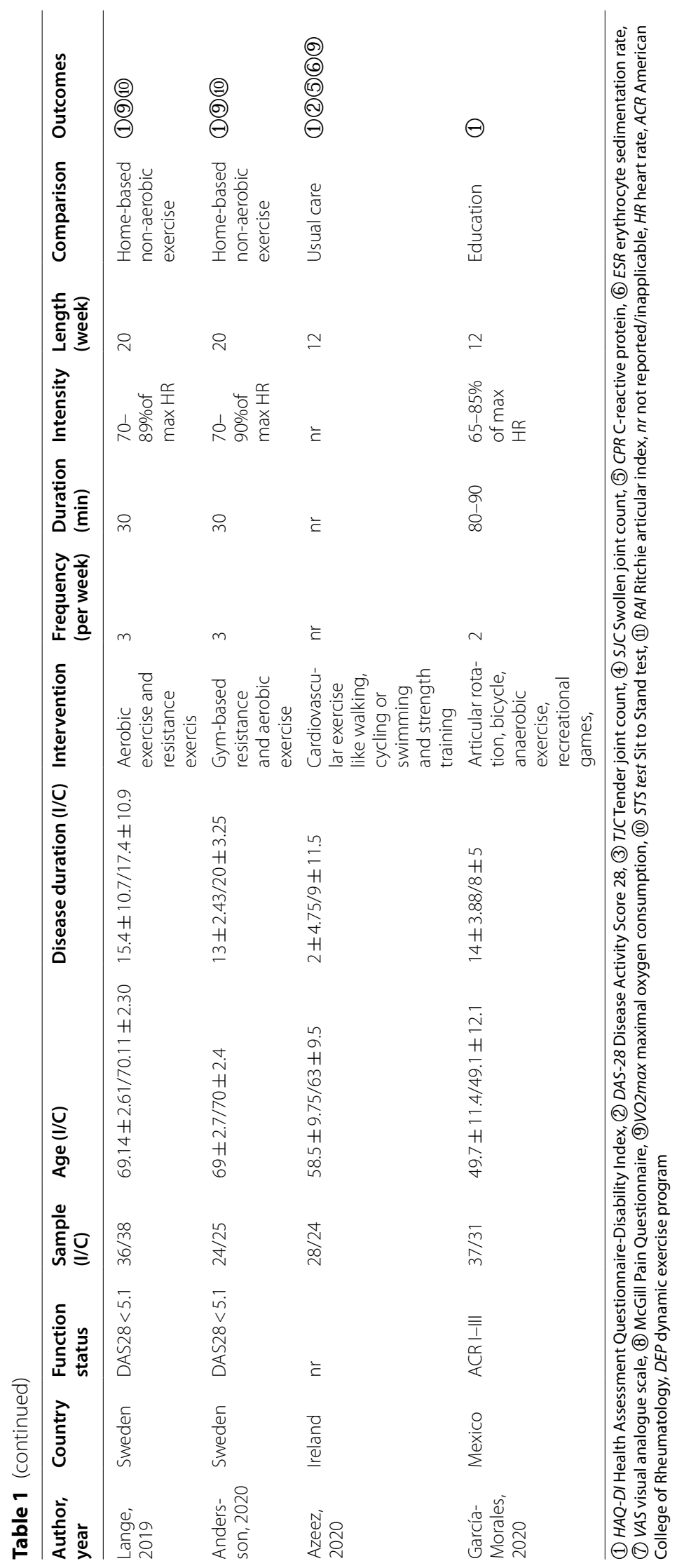



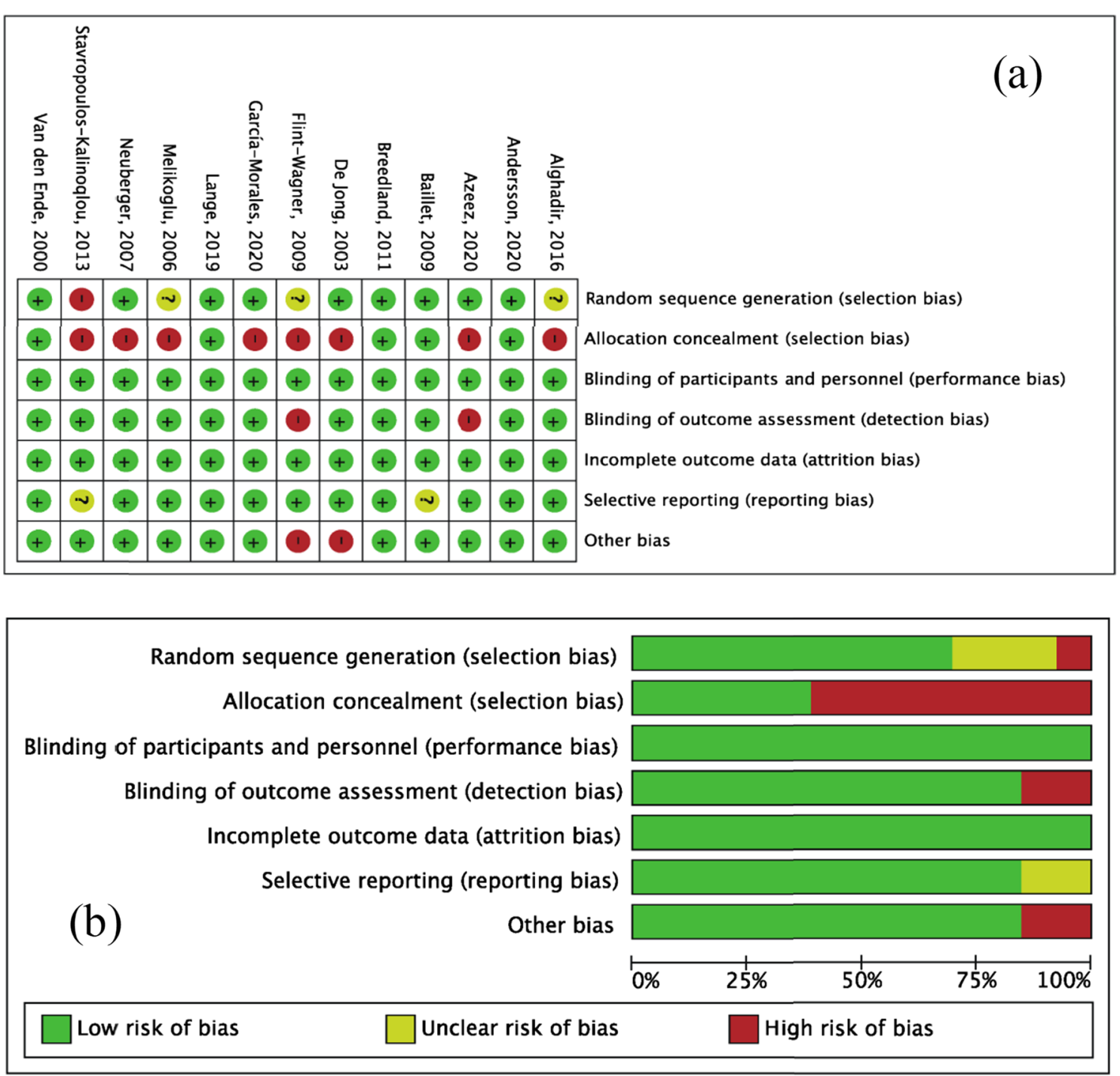

Fig. 2 Risk of bias. a Risk of bias summary and $\mathbf{b}$ risk of bias graph

STS test. The following is a summary of the data evaluated for each outcome in each field.

\section{Functional ability}

HAQ-DI A total of 11 RCTs [33-35, 37, 38, 40-45] reported changes in HAQ-DI scores, including 735 patients (378 patients in the experimental group and 357 patients in the control group). The random-effects model analysis results showed that the total change in the intervention group was significantly lower than that in the control group $[\mathrm{MD}=-0.25,95 \% \mathrm{CI}(-0.38,-0.11)$, $P=0.0002]$. No significant difference was found between long-term and short-term aerobic exercise $(P=0.40)$ (Fig. 3).

\section{Disease activity}

\section{DAS-28.}

Joint count Disease activity, assessed by the DAS28, was recorded in 8 RCTs [33, 34, 37, 39-41, 43, 44], including 573 patients ( 289 patients in the intervention group and 284 patients in the control group). The random-effects model analysis results showed that the DAS28 score change of the intervention group was lower than that of the control group, but the difference was not statistically significant $[\mathrm{MD}=-0.55,95 \% \mathrm{CI}(-1.12,0.01)$, $P=0.06]$. No significant difference was found between long-term and short-term aerobic exercise $(P=0.57)$ (Fig. 4a). 


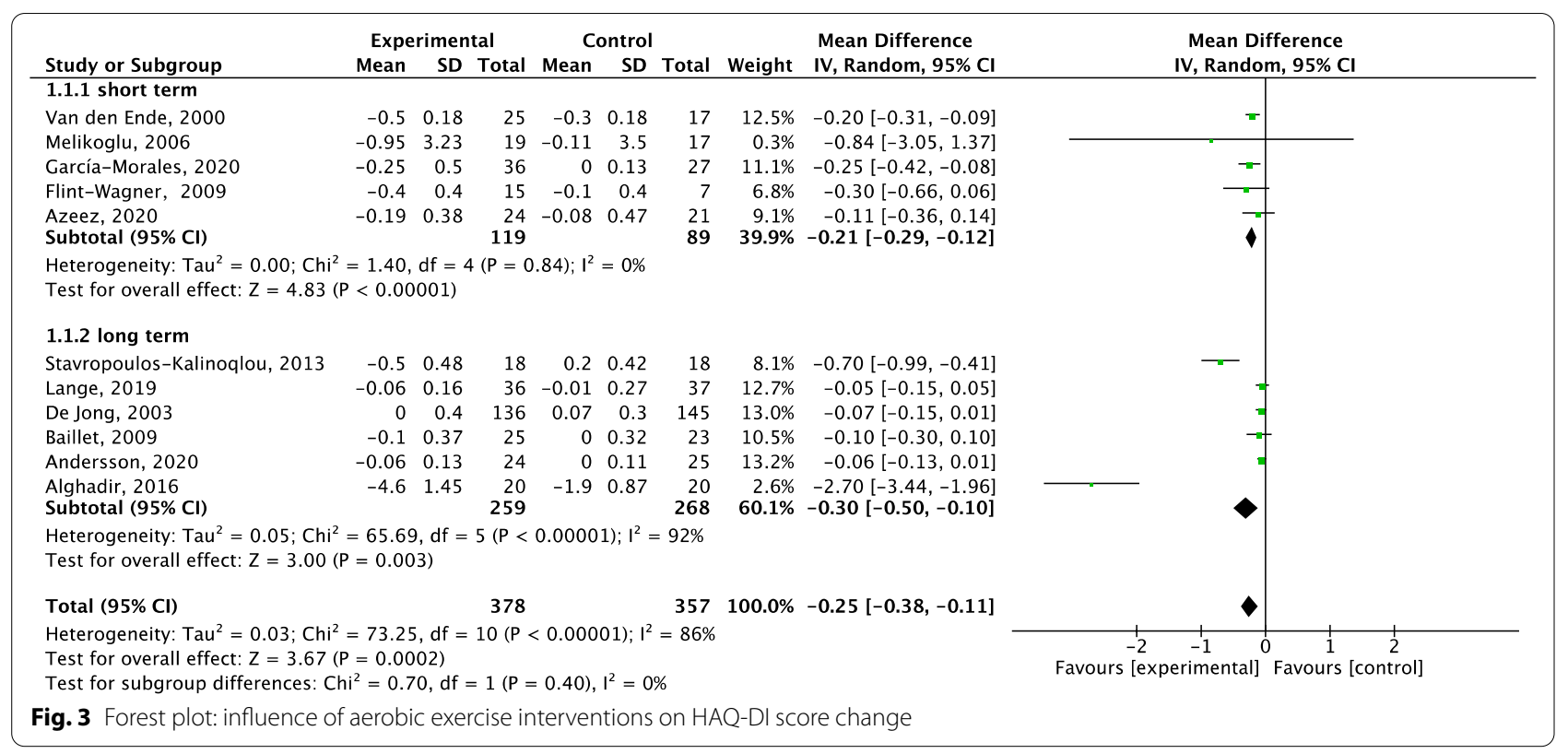

A total of 4 RCTs $[33,35,36,41]$ were included, of 305 patients (155 patients in the experimental group and 150 patients in the control group). RAI was reported in 1 trial [35], SJC in 2 studies [33, 41] and TJC in 2 studies [36, 41]. The random-effects model analysis results showed that the joint count change of the intervention group was lower than that of the control group, but the difference was not statistically significant $[\mathrm{SMD}=-0.59,95 \%$ CI $(-1.26,0.07), P=0.08]$. No significant difference was found between long-term and short-term aerobic exercise $(P=0.51)$ (Fig. $4 \mathrm{~b})$.

\section{Inflammatory markers}

CRP A total of 5 RCTs $[35,36,40,41,43]$ were included, of 298 patients (149 patients in the experimental group and 149 patients in the control group). Random-effects model analysis results showed that the CRP change of the intervention group was lower than that of the control group, but the difference was not statistically significant $[\mathrm{MD}=-1.08,95 \% \mathrm{CI}(-2.20,0.05), P=0.06]$. However, the subgroup analysis showed that long-term aerobic exercise significantly decreased CRP levels $[\mathrm{MD}=-2.28$, 95\% CI $(-3.24,-1.33), P<0.00001]$, but not in the short term (Fig. 5a).

ESR A total of 5 RCTs [33, 35, 36, 41, 44] were included, of 305 patients (157 patients in the intervention group and 148 patients in the control group). The random-effects model analysis results showed that the ESR change of the intervention group was lower than that of the control group, but the difference was not statistically significant $[\mathrm{SMD}=-0.76,95 \% \mathrm{CI}(-1.67,0.14), P=0.10]$. No signif- icant difference was found between long-term and shortterm aerobic exercise $(P=0.20)$ (Fig. $5 b)$.

\section{Pain}

A total of 4 RCTs $[33,35,36,38]$ of short-term interventions were included, of 247 patients (128 patients in the experimental group and 119 patients in the control group). The VAS was reported in 3 trials [33, 35, 38], and the McGill Pain Questionnaire was reported in 1 study [36]. Random-effects model analysis results showed that the pain change of the intervention group was significantly lower than that of the control group $[\mathrm{SMD}=-0.46, \quad 95 \% \quad \mathrm{CI} \quad(-0.90,-0.01), \quad P=0.04]$ (Fig. 6a).

\section{Aerobic capacity}

$V \mathrm{O}_{2} \max$ A total of 5 RCTs [36, 37, 42-44] were included, of 247 patients ( 170 patients in the experimental group and 171 patients in the control group). Randomeffects model analysis results showed that the $\mathrm{VO}_{2} \max$ change of the intervention group was significantly higher than thecontrol group $[\mathrm{MD}=2.41,95 \% \mathrm{CI}(1.36,3.45)$, $P<0.00001]$ In addition, compared to short-term aerobic exercise, long-term aerobic exercise had a better potential improvement trend, although at a significant difference was not shown $(P=0.07)$ (Fig. 6b).

\section{Sit to Stand test}

Two RCTs [42, 43] of long-term interventions were included, of 122 patients (60 patients in the experimental group and 62 patients in the control group). Randomeffects model analysis results showed that the STS score 


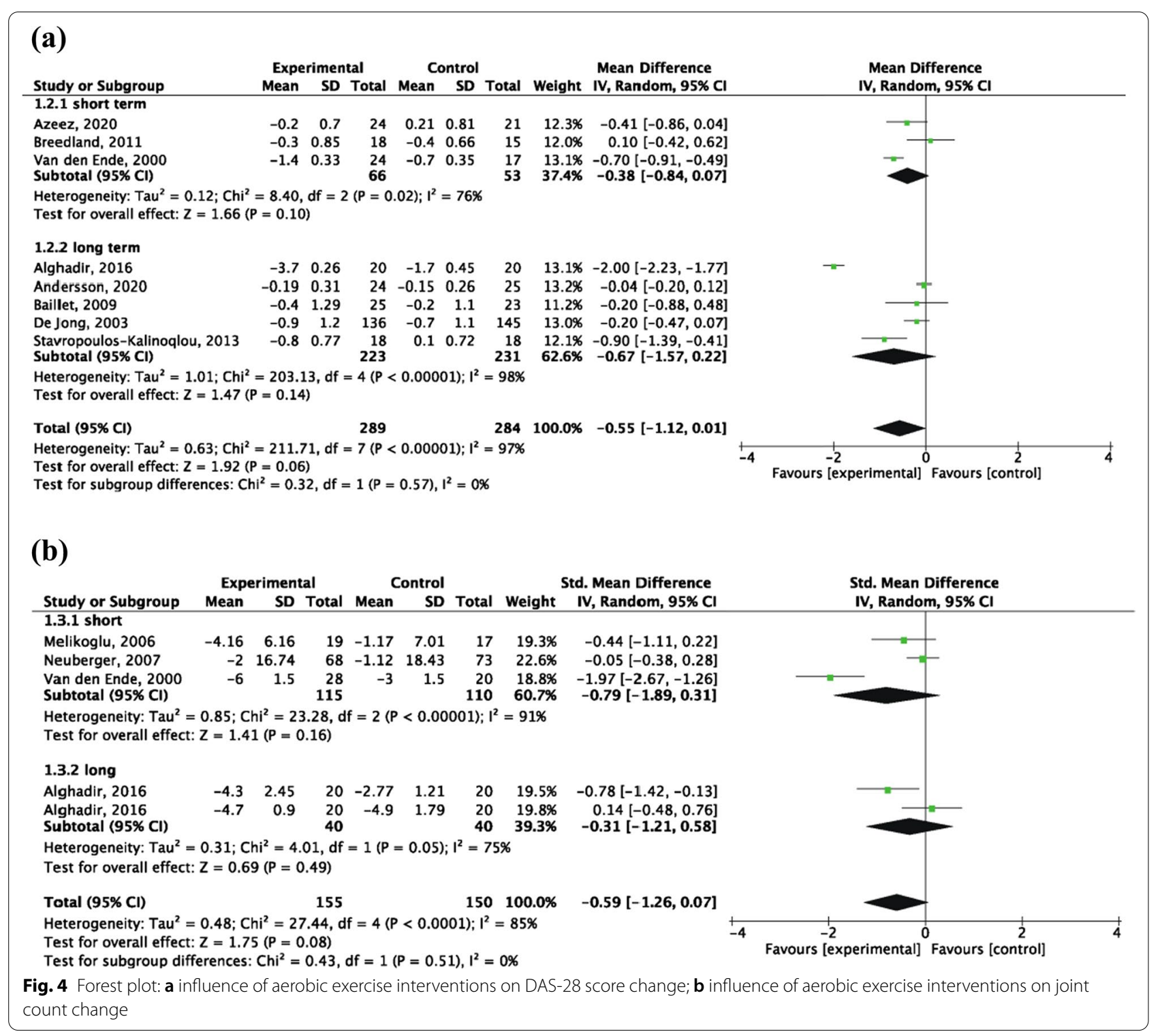

change of the intervention group was significantly higher than that of the control group $[\mathrm{MD}=1.60,95 \% \mathrm{CI}(0.07$, 3.13), $P=0.04$ ] (Fig. 6c).

\section{Adverse events}

Six studies [34-38, 40] reported the safety of the experiment, and all stated that no adverse effects or detrimental disease status effects were found. The pooled results of the $13 \mathrm{RCTs}$ indicate that aerobic exercise exerts no severe side effects and is generally safe for humans with RA.

\section{Sensitivity analysis}

The selected studies were removed one by one, and the overall effect results were recalculated. The overall effect results of functional ability, disease activity, inflammatory markers, joint count and aerobic capacity were relatively stable. After the study of Van den Ende [33] was eliminated, the results of the overall effect of pain score changed $\left(\mathrm{I}^{2}=0 \%, \mathrm{SMD}=-0.64,95 \% \mathrm{CI}[-0.92,-0.35]\right.$, $P<0.0001)$, indicating that the study was a source of heterogeneity and was strongly affecting the results. After removing the study of Andersson [43], the overall effect of aerobic capacity did not change significantly, but the heterogeneity was reduced $\left(\mathrm{I}^{2}=0 \%, \mathrm{MD}=2.03,95 \%\right.$ 


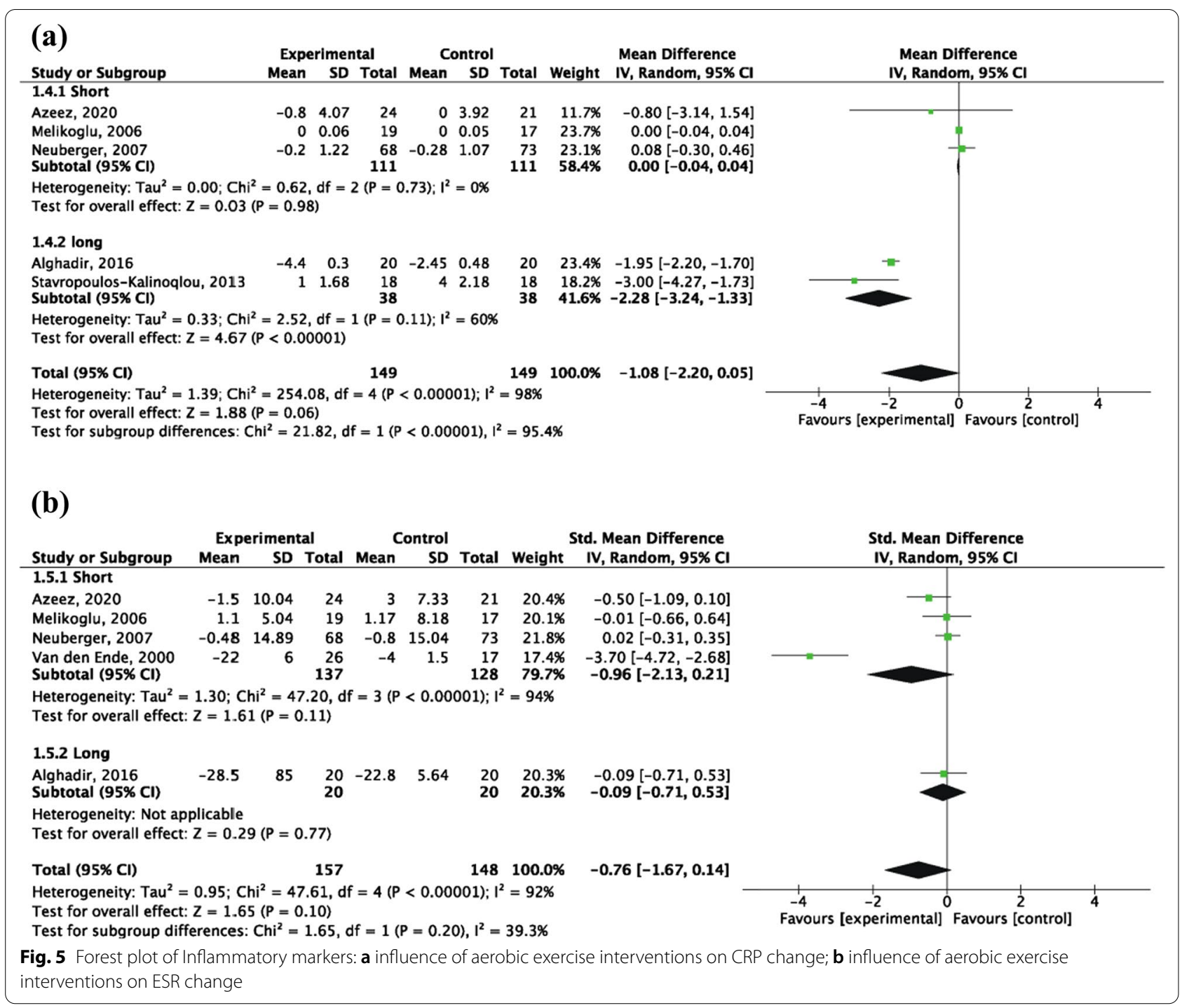

CI $[1.32,2.75], P<0.00001)$, suggesting that this study was the source of heterogeneity in the aerobic capacity database.

\section{GRADE evidence assessment}

GRADEpro was used to evaluate the evidence. In terms of the limitations of the studies, the blinding and allocation concealment reported in some included studies were insufficient, but it had little effect on the experimental results, and they were not downgraded. In terms of inconsistency, most of the indicators were statistically heterogeneous, and they were all downgraded. In terms of indirectness, there was no significant difference between PICO and the research aim. In terms of inaccuracies, some of the outcome sample sizes did not meet the optimal sample size, and some of the outcome effect sizes crossed the invalid line. In terms of publication bias, the included literature does not involve commercial interests, and the literature was searched comprehensively. Currently, no clear evidence has shown a risk of bias, and the grade has not been downgraded. See Table 2 for details.

\section{Discussion}

In general, this systematic review and meta-analysis demonstrated that aerobic exercise could significantly partially ameliorate important RA patient outcomes: functional ability, pain, and aerobic capacity. There was a trend towards a greater reduction in the outcomes of disease activity, joint count, and inflammatory markers, but the differences were not statistically significant in either group. No adverse events were reported, indicating that aerobic exercise is safe for RA patients. 


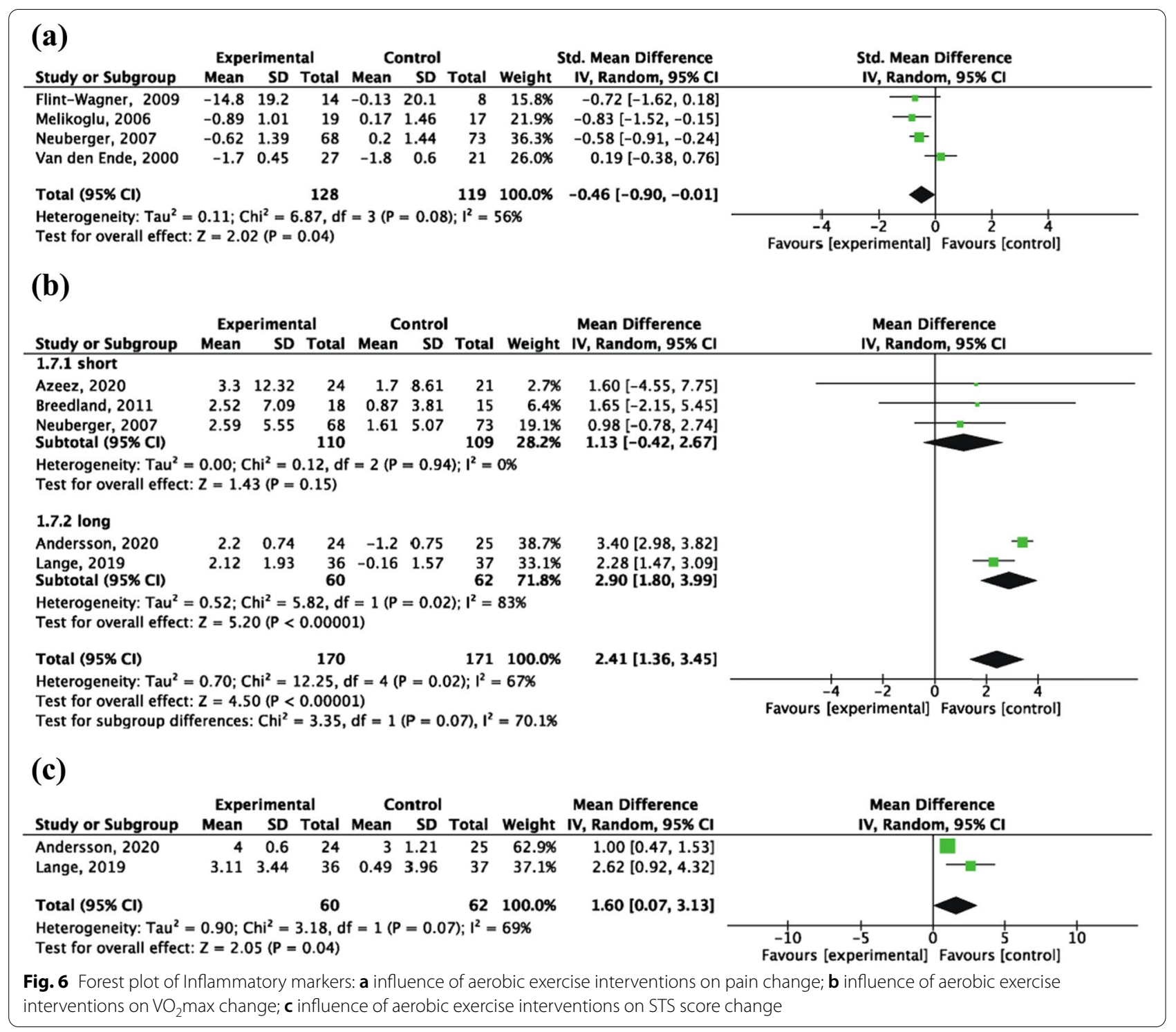

Table 2 Evidence assessment of outcomes

\begin{tabular}{|c|c|c|c|c|}
\hline Outcomes & Anticipated absolute effects $(95 \% \mathrm{Cl})$ & Patients (studies) & Quality of evidence & Rated down reasons \\
\hline Function ability & $0.25 \mathrm{MD}$ lower (0.38-0.11 lower) & 735 (11 RCTs) & Moderate & Inconsistency \\
\hline Disease activity & $0.55 \mathrm{MD}$ lower (1.12 lower to 0.01 higher) & 573 (8 RCTs) & D Low & Inconsistency; imprecision \\
\hline Joint counts & $0.59 \mathrm{MD}$ lower (1.26 lower to 0.07 higher) & 305 (4 RCTs) & Low & Inconsistency; imprecision \\
\hline CRP & $1.08 \mathrm{MD}$ lower (2.20 lower to 0.05 higher) & 298 (5 RCTs) & Low & Inconsistency; imprecision \\
\hline ESR & 0.76 SMD lower ( 1.67 lower to 0.14 higher) & 305 (5 RCTs) & L Low & Inconsistency; imprecision \\
\hline pain & 0.46 SMD lower (0.90-0.01 lower) & 247 (4 RCTs) & $\oplus \oplus \oplus \bigcirc$ Moderate & Imprecision \\
\hline Aerobic capacity & 2.41 MD higher (1.36-3.45 higher) & 247 (5 RCTs) & $\oplus \oplus \bigcirc \bigcirc$ Low & Inconsistency; imprecision \\
\hline STS test & 1.60 MD higher (0.07-3.13 higher) & 122 (2 RCTs) & $\oplus \oplus \bigcirc \bigcirc$ Low & Inconsistency; imprecision \\
\hline
\end{tabular}


RA is often accompanied by poor physical function. The Health Assessment Questionnaire disability index (HAQ-DI) is a popular index for measuring the function of joints by the patients' multidimensional ability to perform activities of daily living [37]. With good reliability and validity, the HAQ-DI helps to detect functional changes, monitor the severity of disease, and predict all-cause mortality in RA patients [46-48]. This study's analysis result shows that aerobic exercise can effectively reduce the HAQ-DI score, which is consistent with the analysis result of Bailet [49], indicating that aerobic exercise is of great significance for improving functional ability.

Another major symptom of RA is pain, which classically occurs in the small joints of the hands, wrists and feet [50]. Despite the successful clinical application of medicine, pain persists for many RA patients. Among the 4 studies reporting the effects of aerobic exercise on the pain of RA patients, 3 used the VAS scale, 1 used the McGill Pain Questionnaire, and all were short-term interventions ( $\leq 16$ weeks). The results showed that aerobic exercise has a pain-relieving effect, and a similar reduction in pain has been found in previous studies $[49,51]$. An effect of aerobic exercise on pain relief has been found for chronic low back pain [52], knee osteoarthritis [53] and other conditions. The mechanism may be related to the modification and influence of exercise on central pain processing and pain sensitivity [54].

Aerobic capacity is reflected in the value of $\mathrm{VO}_{2} \mathrm{max}$, a strong and independent predictor of overall mortality, and it is associated with disease activity and cardiovascular risk factors in early rheumatoid arthritis $[44,55]$. This research found improved $\mathrm{VO}_{2}$ max levels after aerobic exercise intervention; similarly, an absolute improvement in cardiorespiratory fitness in RA patients was shown after a 10-week high-intensity interval walk training programme [56]. The results demonstrated that exercise could improve aerobic capacity and reduce the risk of CVD and mortality in RA patients.

The advantage of aerobic exercise is also reflected in the improvement of the STS score, which is used to evaluate muscle strength of the lower limbs, mobility and risk of falls [57]. Aerobic exercise may increase body mobility, thereby reducing the impairment of functional status in RA patients. In addition, functional ability represents the main factor related to high fall prevalence in RA patients [58], suggesting that STS and HAQ can together be listed as the main outcomes for discussion in future studies.

The three indicators reflecting disease activity, including DAS-28, joint counts and inflammatory markers, were not significantly improved compared with the control group. This result is consistent with previous studies $[49,59]$. Large heterogeneity was seen in the results of three outcomes, indicating systematic differences among the included studies, resulting in the reliability of the overall results being less stable. Therefore, the significance of the included studies concerning the change in DAS-28, joint counts and inflammatory markers cannot be reliably interpreted. Notably, subgroup analysis showed that long-term ( $>16$ weeks) aerobic exercise intervention resulted in a significant reduction in CRP. Subgroup analysis indicated that long-term interventions tended to be more effective than short-term exercise in terms of functional ability, disease activity, inflammatory markers and aerobic capacity indicators. This shows a trend towards better improvement with long-term exercise for RA patients. However, due to the small number of included articles and samples, more evidence is needed in the future to validate these findings.

A well-balanced duration, frequency and length of training is essential for RA patients. The ACSM recommends that most adults engage in moderate-intensity cardiorespiratory exercise training for $\geq 30 \mathrm{~min} \cdot$ day on $\geq 5$ days.week for a total of $\geq 150 \mathrm{~min} \cdot$ week [60]. The included articles did not focus on clearly demonstrating the impact of exercise time and frequency on the results. Additional studies are needed in the future to explore the dose response relationship between exercise intensity and RA symptoms.

Through GRADE classification, this study found varying quality of evidence to show the effects of aerobic exercise on RA patient outcomes. In terms of functional ability, moderate-quality evidence indicated that aerobic exercise could reduce HAQ scores. Low-quality evidence indicated that aerobic exercise reduced the DAS-28 score and joint counts and decreased inflammatory markers without a significant effect. Moderate-quality evidence suggests that aerobic exercise can alleviate RA patients' pain. Low-quality evidence showed that aerobic exercise significantly increased the VO2max and STST scores of RA patients.

Compared with previously published reviews, this meta-analysis was more focused on aerobic patterns, incorporated more new studies, summarized the latest evidence of the effect of aerobic exercise programs in RA, and integrated more outcome indicators than have been analysed before, such as STS score and $\mathrm{VO}_{2} \max$ levels $[17,25,61,62]$. Meanwhile, this study has certain limitations. First, due to the limitations of the included literature, it does not include indicators such as quality of life, emotional health, fatigue, etc. Second, part of the data included in the combined analysis study was obtained after conversion, and there may be slight deviations from the original data. Some indicators appeared, only in two studies. Moreover, the methodological quality of the included studies was generally low to moderate, 
calling for more extensive and higher-quality studies in the future. The advantage of this review is its up-todate, systematic and comprehensive literature search on related topics and innovative attention to two new indicators: aerobic capacity and STS.

\section{Conclusion}

Current research shows that aerobic exercise has a beneficial effect on the functional capacity, pain and aerobic exercise capacity of rheumatoid arthritis patients and exerts no adverse events. However, there is no substantial evidence to prove that aerobic exercise significantly affects disease activity, joint count, and inflammatory markers in RA patients. More RCTs with larger sample sizes and higher quality are warranted.

\section{Abbreviations}

RA: Rheumatoid arthritis; NSAIDs: Non-steroidal anti-inflammatory drugs; DMARDs: Disease-modifying antirheumatic drugs; VO2max: Peak oxygen consumption; RCTs: Randomized controlled trials; HAQ-DI: The Health Assessment Questionnaire-Disability index; DAS28: The Disease Activity Score in 28 joints; TJC: Tender joint count; SJC: Swollen joint count; RAI: The Ritchie Articular Index; CRP: C-reactive protein; ESR: Erythrocyte sedimentation rate; VAS: Pain on visual analog scale; STS: Sit to Stand test; GRADE: The Grading of Recommendations Assessment, Development, and Evaluation.

\section{Acknowledgements}

Not applicable.

\section{Authors' contributions}

$H Y$ designed the study and wrote the paper. $H Y$ and $X Y$ performed the literature database search, data collection and extraction. HY, HW and LLW performed data analysis and rationalization of the results. QW and G-HX supervised all aspects of the study. All authors read and approved the final manuscript.

\section{Funding}

This study was supported by the Natural Science Research Project of Universities in Jiangsu Province, Research on the Synergistic Regulation and Mechanism of Combined Exercise on Postmenopausal Osteoporosis (20KJB320003) and the Nursing Advantageous Discipline Construction Project in Nanjing University of Chinese medicine, Jiangsu Universities (2019YSHL017). They helped with research design and provided a platform for this research to be conducted.

\section{Availability of data and materials}

The PubMed, Cochrane Library, Web of Science, Embase, CNKI, WanFang Data and VIP databases were searched for eligible articles. Additionally, this study was registered with the PROSPERO database (registration number: CRD42021242953). Full data for this research is available through the corresponding author upon request.

\section{Declarations}

Ethics approval and consent to participate Not applicable.

\section{Consent for publication}

Not applicable.

\section{Competing interests}

The authors have no potential conflict of interest to declare.
Received: 21 October 2021 Accepted: 27 January 2022

Published online: 05 February 2022

\section{References}

1. Alhajeri H, Abutiban F, Al-Adsani W, et al. Kuwait association of rheumatology 2018 treatment recommendations for patients with rheumatoid arthritis. Rheumatol Int. 2019;9(9):1483-97. https://doi.org/10.1007/ s00296-019-04372-y.

2. Cross M, Smith E, Hoy D, Carmona L, Wolfe F, Vos T, Williams B, Gabriel S, Lassere M, Johns N, Buchbinder R, Woolf A, March L. The global burden of rheumatoid arthritis: estimates from the global burden of disease 2010 study. Ann Rheum Dis. 2014;73(7):1316-22. https://doi.org/10.1136/ annrheumdis-2013-204627.

3. Park JYE, Howren AM, Davidson E, De Vera MA. Insights on mental health when living with rheumatoid arthritis: a descriptive qualitative study of threads on the Reddit website. BMC Rheumatol. 2020;4(1):62. https://doi. org/10.21203/rs.3.rs-29632/v1

4. Safiri S, Kolahi AA, Hoy D, et al. Global, regional and national burden of rheumatoid arthritis 1990-2017: a systematic analysis of the Global Burden of Disease study 2017. Ann Rheum Dis. 2019;78(11):1463-71. https:// doi.org/10.1136/annrheumdis-2019-215920.

5. Lee YH, Tsou HK, Kao SL, Gau SY, Bai YC, Lin MC, Wei JC. Patients with rheumatoid arthritis increased risk of developing osteoarthritis: a nationwide population-based cohort study in Taiwan. Front Med. 2020;7:392. https://doi.org/10.3389/fmed.2020.00392.

6. Ho CTK, Mok CC, Cheung TT, Kwok KY, Yip RML, Hong Kong Society of Rheumatology. Management of rheumatoid arthritis: 2019 updated consensus recommendations from the Hong Kong Society of Rheumatology. Clin Rheumatol. 2019;38(12):3331-50. https://doi.org/10.1007/ s10067-019-04761-5.

7. Galligan CL, Keystone EC, Fish EN. Fibrocyte and T cell interactions promote disease pathogenesis in rheumatoid arthritis. J Autoimmun. 2016;69:38-50. https://doi.org/10.1016/j.jaut.2016.02.008

8. Fang Q, Zhou C, Nandakumar KS. Molecular and cellular pathways contributing to joint damage in rheumatoid arthritis. Mediators Inflamm. 2020. https://doi.org/10.1155/2020/3830212.

9. van Walsem A, Pandhi S, Nixon RM, Guyot P, Karabis A, Moore RA. Relative benefit-risk comparing diclofenac to other traditional non-steroidal antiinflammatory drugs and cyclooxygenase-2 inhibitors in patients with osteoarthritis or rheumatoid arthritis: a network meta-analysis. Arthritis Res Ther. 2015;17(1):66. https://doi.org/10.1186/s13075-015-0554-0.

10. Smolen JS, Landewé RBM, Bijlsma JWJ. EULAR recommendations for the management of rheumatoid arthritis with synthetic and biological disease-modifying antirheumatic drugs: 2019 update. Ann Rheum Dis. 2020;79(6):685-99. https://doi.org/10.1136/annrheumdis-2019-216655.

11. Lopez-Pedrera C, Barbarroja N, Patiño-Trives AM, Luque-Tévar M, Collantes-Estevez E, Escudero-Contreras A, Pérez-Sánchez C. Effects of biological therapies on molecular features of rheumatoid arthritis. Int J Mol Sci. 2020;21(23):9067. https://doi.org/10.3390/ijms21239067.

12. Chi TY, Zhu HM, Zhang M. Risk factors associated with nonsteroidal antiinflammatory drugs (NSAIDs)-induced gastrointestinal bleeding resulting on people over 60 years old in Beijing. Medicine. 2018;97(18): e0665. https://doi.org/10.1097/MD.0000000000010665.

13. Singh JA, Wells GA, Christensen R, et al. Adverse effects of biologics: a network meta-analysis and Cochrane overview. Cochrane Database Syst Rev. 2011;2011(2):CD008794. https://doi.org/10.1002/14651858.CD008 794.pub2.

14. Conn VS, Hafdahl AR, Minor MA, Nielsen PJ. Physical activity interventions among adults with arthritis: meta-analysis of outcomes. Semin Arthritis Rheum. 2008;37(5):307-16. https://doi.org/10.1016/j.semarthrit.2007.07. 006.

15. Metsios GS, Kitas GD. Physical activity, exercise and rheumatoid arthritis: effectiveness, mechanisms and implementation. Best Pract Res Clin Rheumatol. 2019;32(5):669-82. https://doi.org/10.1016/j.berh.2019.03. 013.

16. Dasso NA. How is exercise different from physical activity? A concept analysis. Nurs Forum. 2019;54(1):45-52. https://doi.org/10.1111/nuf. 12296. 
17. Hu H, Xu A, Gao C, Wang Z, Wu X. The effect of physical exercise on rheumatoid arthritis: an overview of systematic reviews and meta-analysis. J Adv Nurs. 2020;77(2):506-22. https://doi.org/10.1111/jan.14574.

18. Fujii Y, Inoue H, Arai Y, Shimomura S, Nakagawa S, Kishida T, Tsuchida S, Kamada Y, Kaihara K, Shirai T, Terauchi R, Toyama S, Ikoma K, Mazda $\mathrm{O}$, Mikami Y. Treadmill running in established phase arthritis inhibits joint destruction in rat rheumatoid arthritis models. Int J Mol Sci. 2019;20(20):5100. https://doi.org/10.3390/ijms20205100.

19. Rausch Osthoff AK, Niedermann K, Braun J, et al. 2018 EULAR recommendations for physical activity in people with inflammatory arthritis and osteoarthritis. Ann Rheum Dis. 2018;77(9):1251-60. https://doi.org/10. 1136/annrheumdis-2018-213585.

20. Verhoeve F, Tordi N, Prati C, et al. Physical activity in patients with rheumatoid arthritis. Joint Bone Spine. 2016;83(3):265-70. https://doi.org/10 1016/j.jbspin.2015.10.002.

21. Di Giuseppe D, Bottai M, Askling J, Wolk A. Physical activity and risk of rheumatoid arthritis in women: a population-based prospective study. Arthritis Res Ther. 2015;17(1):40. https://doi.org/10.1186/ s13075-015-0560-2.

22. Rios JL, Bomhof MR, Reimer RA, Hart DA, Collins KH, Herzog W. Protective effect of prebiotic and exercise intervention on knee health in a rat model of diet-induced obesity. Sci Rep. 2019;9(1):3893. https://doi.org/10. 1038/s41598-019-40601-x

23. Melikoglu MA, Senel K. THU0556Aerobic exercise training improves cardiovascular risk in patients with rheumatoid arthritis. Ann Rheum Dis. 2013;72:A352. https://doi.org/10.1136/annrheumdis-2013-eular.1084.

24. Løppenthin K, Esbensen BA, Jennum P, Østergaard M, Christensen JF, Thomsen T, Bech JS, Midtgaard J. Effect of intermittent aerobic exercise on sleep quality and sleep disturbances in patients with rheumatoid arthritis-design of a randomized controlled trial. BMC Musculoskel Dis. 2014;15:49. https://doi.org/10.1186/1471-2474-15-49.

25. Hurkmans E, van der Giesen FJ, Vliet Vlieland TP, Schoones J, Van den Ende EC. Dynamic exercise programs (aerobic capacity and/or muscle strength training) in patients with rheumatoid arthritis. Cochrane Database Syst Rev. 2009;2009(4):CD006853. https://doi.org/10.1002/14651858.CD006 853.pub2.

26. He CS, Xu FY, Yu Q, Yang DQ. Effects of aerobic exercise on quality of life in patients with rheumatoid arthritis. Chin J Phys Med Rehabil. 2004;26(9):555-7. https://doi.org/10.3760/j:issn:0254-1424.2004.09.016.

27. Chapman JR. Editorial perspective: time for another grading systemfrom PRISMA to AMSTAR 2. Glob Spine J. 2020;10(5):674-5. https://doi. org/10.1177/2192568220920889.

28. Moher D, Liberati A, Tetzlaff J, Altman DG, The PRISMA Group. Preferred reporting items for systematic reviews and meta-analyses: the PRISMA statement. BMJ. 2009;7:1-8. https://doi.org/10.1136/bmj.b2535.

29. Aletaha D, Neogi T, Silman AJ, et al. 2010 Rheumatoid arthritis classification criteria: an American College of Rheumatology/European League Against Rheumatism collaborative initiative. Ann Rheum Dis. 2010;69(9):1580-8. https://doi.org/10.1136/ard.2010.138461.

30. Oude Voshaar MAH, Das Gupta Z, Bijlsma JWJ, et al. International consortium for health outcome measurement set of outcomes that matter to people living with inflammatory arthritis: consensus from an international working group. Arthritis Care Res. 2019;71(12):1556-65. https://doi. org/10.1002/acr.23799.

31. Higgins JPT, Thomas J, Chandler J, Cumpston M, LiT, Page MJ, Welch VA (eds) (2021) Cochrane handbook for systematic reviews of interventions version 6.2(updated February 2021). Cochrane. www.training.cochrane. org/handbook. Accessed 2 Mar 2021

32. GRADEpro GDT: GRADEpro Guideline Development Tool (2015) McMaster University (developed by Evidence Prime), Hamilton (ON)

33. Van den Ende CH, Breedveld FC, le Cessie S, Dijkmans BA, de Mug AW, Hazes JM. Effect of intensive exercise on patients with active rheumatoid arthritis: a randomised clinical trial. Ann Rheum Dis. 2000;59(8):615-21. https://doi.org/10.1136/ard.59.8.615.

34. de Jong Z, Munneke M, Zwinderman AH, Kroon HM, Jansen A, Ronday $\mathrm{KH}$, van Schaardenburg D, Dijkmans BA, Van den Ende CH, Breedveld FC, Vliet Vlieland TP, Hazes JM. Is a long-term high-intensity exercise program effective and safe in patients with rheumatoid arthritis? Results of a randomized controlled trial. Arthritis Rheum. 2003;48(9):2415-24. https:// doi.org/10.1002/art.11216.
35. Melikoglu MA, Karatay S, Senel K, Akcay F. Association between dynamic exercise therapy and IGF-1 and IGFBP-3 concentrations in the patients with rheumatoid arthritis. Rheumatol Int. 2006;26(4):309-13. https://doi. org/10.1007/s00296-005-0605-y.

36. Neuberger GB, Aaronson LS, Gajewski B, Embretson SE, Cagle PE, Loudon $J K$, Miller PA. Predictors of exercise and effects of exercise on symptoms, function, aerobic fitness, and disease outcomes of rheumatoid arthritis. Arthritis Rheum. 2007;57(6):943-52. https://doi.org/10.1002/art.22903.

37. Baillet $A$, Payraud $E$, Niderprim VA, Nissen MJ, Allenet $B$, François $P$, Grange $L$, Casez P, Juvin R, Gaudin P. A dynamic exercise programme to improve patients' disability in rheumatoid arthritis: a prospective randomized controlled trial. Rheumatology (Oxford). 2009;48(4):410-5. https://doi.org/ 10.1093/rheumatology/ken511.

38. Flint-Wagner HG, Lisse J, Lohman TG, Going SB, Guido T, Cussler E, Gates D, Yocum DE. Assessment of a sixteen-week training program on strength, pain, and function in rheumatoid arthritis patients. J Clin Rheumatol. 2009;15(4):165-71. https://doi.org/10.1097/RHU.0b013e3181 90f95f.

39. Breedland I, van Scheppingen C, Leijsma M, Verheij-Jansen NP, van Weert E. Effects of a group-based exercise and educational program on physical performance and disease self-management in rheumatoid arthritis: a randomized controlled study. Phys Ther. 2011;91(6):879-93. https://doi. org/10.2522/ptj.20090010.

40. Stavropoulos-Kalinoglou A, Metsios GS, Veldhuijzen van Zanten JJ, Nightingale P, Kitas GD, Koutedakis Y. Individualised aerobic and resistance exercise training improves cardiorespiratory fitness and reduces cardiovascular risk in patients with rheumatoid arthritis. Ann Rheum Dis. 2013;72(11):1819-25. https://doi.org/10.1136/annrheumdis-2012-202075.

41. Alghadir AH, Gabr SA, Al-Eisa ES. Green tea and exercise interventions as nondrug remedies in geriatric patients with rheumatoid arthritis. J Phys Ther Sci. 2016;28(10):2820-9. https://doi.org/10.1589/jpts.28.2820.

42. Lange E, Kucharski D, Svedlund S, Svensson K, Bertholds G, Gjertsson I, Mannerkorpi K. Effects of aerobic and resistance exercise in older adults with rheumatoid arthritis: a randomized controlled trial. Arthritis Care Res (Hoboken). 2019;71(1):61-70. https://doi.org/10.1002/acr.23589.

43. Andersson SEM, Lange E, Kucharski D, Svedlund S, Önnheim K, Bergquist M, Josefsson E, Lord JM, Mårtensson IL, Mannerkorpi K, Gjertsson I. Moderate- to high intensity aerobic and resistance exercise reduces peripheral blood regulatory cell populations in older adults with rheumatoid arthritis. Immun Ageing. 2020;16(17):12. https://doi.org/10.1186/ s12979-020-00184-y.

44. Azeez M, Clancy C, O'Dwyer T, Lahiff C, Wilson F, Cunnane G. Benefits of exercise in patients with rheumatoid arthritis: a randomized controlled trial of a patient-specific exercise programme. Clin Rheumatol. 2020;39(6):1783-92. https://doi.org/10.1007/s10067-020-04937-4.

45. García-Morales JM, Lozada-Mellado M, Hinojosa-Azaola A, Llorente L, Ogata-Medel M, Pineda-Juárez JA, Alcocer-Varela J, Cervantes-Gaytán R, Castillo-Martínez L. Effect of a dynamic exercise program in combination with mediterranean diet on quality of life in women with rheumatoid arthritis. J Clin Rheumatol. 2020;26(7S Suppl 2):S116-22. https://doi.org/ 10.1097/RHU.00000000000001064.

46. Cuperus N, Mahler EA, Vliet Vlieland TP, Hoogeboom TJ, van den Ende $\mathrm{CH}$. Measurement properties of the health assessment questionnaire disability index for generalized osteoarthritis. Rheumatology (Oxford). 2015;54(5):821-6. https://doi.org/10.1093/rheumatology/keu386.

47. Yoshii I, Chijiwa T, Sawada N. Validity of adopting a Health Assessment Questionnaire Disability Index less than 0.5 as a target in elderly rheumatoid arthritis patients. Clin Rheumatol. 2019;38(12):3351-60. https://doi. org/10.1007/s10067-019-04692-1.

48. Fatima S, Schieir O, Valois MF, Bartlett SJ, Bessette L, Boire G, Hazlewood G, Hitchon C, Keystone EC, Tin D, Thorne C, Bykerk VP, Pope JE, Investigators CATCH. Health assessment questionnaire at one year predicts all-cause mortality in patients with early rheumatoid arthritis. Arthritis Rheumatol. 2021;73(2):197-202. https://doi.org/10.1002/art.41513.

49. Baillet A, Zeboulon N, Gossec L, Combescure C, Bodin LA, Juvin R, Dougados M, Gaudin P. Efficacy of cardiorespiratory aerobic exercise in rheumatoid arthritis: meta-analysis of randomized controlled trials. Arthritis Care Res (Hoboken). 2010;62(7):984-92. https://doi.org/10.1002/acr.20146.

50. Zhang A, Lee YC. Mechanisms for joint pain in rheumatoid arthritis (RA): from cytokines to central sensitization. Curr Osteoporos Rep. 2018;16(5):603-10. https://doi.org/10.1007/s11914-018-0473-5. 
51. Hurkmans E, van der Giesen FJ, Vliet Vlieland TP, Schoones J, Van den Ende EC. Dynamic exercise programs (aerobic capacity and/or muscle strength training) in patients with rheumatoid arthritis. Cochrane Database Syst Rev. 2009;7:CD006853. https://doi.org/10.1002/14651858.CD006853. pub2.

52. Meng XG, Yue SW. Efficacy of aerobic exercise for treatment of chronic low back pain: a meta-analysis. Am J Phys Med Rehabil. 2015;94(5):35865. https://doi.org/10.1097/PHM.0000000000000188.

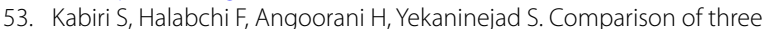
modes of aerobic exercise combined with resistance training on the pain and function of patients with knee osteoarthritis: a randomized controlled trial. Phys Ther Sport. 2018;32:22-8. https://doi.org/10.1016/j. ptsp.2018.04.001.

54. Katz P, Andonian BJ, Huffman KM. Benefits and promotion of physical activity in rheumatoid arthritis. Curr Opin Rheumatol. 2020;32(3):307-14. https://doi.org/10.1097/BOR.0000000000000669.

55. Ångström L, Hörnberg K, Sundström B, Jonsson SW, Södergren A. Aerobic capacity is associated with disease activity and cardiovascular risk factors in early rheumatoid arthritis. Physiother Res Int. 2020;25(3): e1833. https:// doi.org/10.1002/pri.1833.

56. Bartlett DB, Willis LH, Slentz CA, Hoselton A, Kelly L, Huebner JL, Kraus VB, Moss J, Muehlbauer MJ, Spielmann G, Kraus WE, Lord JM, Huffman KM. Ten weeks of high-intensity interval walk training is associated with reduced disease activity and improved innate immune function in older adults with rheumatoid arthritis: a pilot study. Arthritis Res Ther. 2018;20(1):127. https://doi.org/10.1186/s13075-018-1624-x.

57. Marques WV, Cruz VA, Rego J, Silva NA. The impact of comorbidities on the physical function in patients with rheumatoid arthritis. Rev Bras Reumatol Engl Ed. 2016;56(1):14-22. https://doi.org/10.1016/j.rbre.2015. 07.009 .

58. Marques WV, Cruz VA, Rego J, Silva NA. Influência da capacidade funcional no risco de quedas em adultos com artrite reumatoide [The influence of physical function on the risk of falls among adults with rheumatoid arthritis]. Rev Bras Reumatol. 2014;54(5):404-8. https://doi.org/10. 1016/j.rbr.2014.03.019.

59. Burghardt RD, Kazim MA, Rüther W, Niemeier A, Strahl A. The impact of physical activity on serum levels of inflammatory markers in rheumatoid arthritis: a systematic literature review. Rheumatol Int. 2019;39(5):793-804. https://doi.org/10.1007/s00296-019-04284-х.1007/ s00296-019-04284-x.

60. American College of Sports Medicine position stand. Quantity and quality of exercise for developing and maintaining cardiorespiratory, musculoskeletal, and neuromotor fitness in apparently healthy adults: guidance for prescribing exercise. Med Sci Sports Exerc. 2011;43(7):133459. https://doi.org/10.1249/MSS.0b013e318213fefb.

61. Sobue Y, Kojima T, Ito H, Nishida K, Matsushita I, Kaneko Y, Kishimoto M, Kohno M, Sugihara T, Seto Y, Tanaka E, Nakayama T, Hirata S, Murashima A, Morinobu A, Mori M, Kojima M, Kawahito Y, Harigai M. Does exercise therapy improve patient-reported outcomes in rheumatoid arthritis? A systematic review and meta-analysis for the update of the $2020 \mathrm{JCR}$ guidelines for the management of rheumatoid arthritis. Mod Rheumatol. 2021;22:1-14. https://doi.org/10.1080/14397595.2021.1886653.

62. Kelley GA, Kelley KS, Callahan LF. Aerobic exercise and fatique in rheumatoid arthritis participants: a meta-analysis using the minimal important difference approach. Arthritis Care Res (Hoboken). 2018;70(12):1735-9. https://doi.org/10.1002/acr.23570.

\section{Publisher's Note}

Springer Nature remains neutral with regard to jurisdictional claims in published maps and institutional affiliations.

Ready to submit your research? Choose BMC and benefit from:

- fast, convenient online submission

- thorough peer review by experienced researchers in your field

- rapid publication on acceptance

- support for research data, including large and complex data types

- gold Open Access which fosters wider collaboration and increased citations

- maximum visibility for your research: over $100 \mathrm{M}$ website views per year

At BMC, research is always in progress.

Learn more biomedcentral.com/submissions 